\title{
PERANCANGAN IDENTITAS VISUAL DAN PROMOSI SASIRANGAN BANJARBARU
}

\author{
Azizah Septiningtyas ${ }^{1}$, Didit Widiatmoko Soewardikoen ${ }^{2}$ \\ 1,2Universitas Telkom
}

\begin{tabular}{|c|c|c|}
\hline Received: 24 Agustus 2017 & Revised: 26 Januari 2018 & Accepted: 29 Januari 2018 \\
\hline \multicolumn{3}{|c|}{ Available online at: bit.do/demandia }
\end{tabular}

\begin{abstract}
Abstrak : Sasirangan sebagai warisan budaya merupakan kain khas dari Suku Banjar Kalimantan Selatan yang memiliki ciri khas pada motif dan warna yang cerah. Ciri kerajinan ini khususnya di Kota Banjarbaru, diinovasi dengan penambahan bordir yang membuat motif sirang lebih terlihat cerah dan timbul dibandingkan Sasirangan biasa. Namun awareness masyarakat mengenai Sasirangan Bordir Banjarbar masih kurang karena promosi yang dilakukan belum optimal. Hal ini menyebabkan pemasaran dan penjualan Sasirangan Bordir Banjarbaru belum memenuhi target. Untuk pengumpulan data, Instrumen yang digunakan adalah pengamatan visual, wawancara, kuesioner dan studi pustaka. Kemudian data yang terkumpul dianalisis dengan menggunakan matriks perbandingan. Dalam penelitian ini dapat disimpulkan bahwa perancangan identitas visual dan kemasan serta melakukan promosi yang sesuai dan tepat sasaran sangat diperlukan agar masyarakat dan wisatawan menyadari akan adanya produk ini. Hasil perancangan ini difokuskan pada unsur etnik dan inovasi produk yang divisualisasikan dengan tren visual dan desain saat ini. Hasil perancangan ini mampu membantu pihak Dekranasda sebagai pengembang dan fasilitator untuk membangun kesadaran merk masyarakat dan wisatawan serta meningkatkan penjualan Sasirangan Banjarbaru.

Kata Kunci : Bordir, Sasirangan Banjarbaru, visual branding
\end{abstract}

Abstract: Sasirangan as a cultural heritage is a special cloth from Banjar Tribe, South Kalimantan, that has a certain characteristic on the motif and bright colors. Especially in the city of Banjarbaru this craft characteristic is innovated with the addition of embroidery that makes the motifs look brighter and exposed compared to ordinary Sasirangan fabric. However the awareness of the local people about Sasirangan Bordir Banjarbaru are still less because of the insufficient existing campaign. It causes the marketing and sales Sasirangan Bordir Banjarbaru cannot accomplish the target. For data collection, the instruments used are visual observation, interview, questionnaire and literature study. Then the collected data is analyzed by using comparison matrix. In this study it can be concluded that the design of visual identity and packaging as well as promotion and appropriate target is needed so that local people and tourists are aware of this product. The results of this design are focused on ethnic elements and product innovations visualized with current design trends. The results of this design is able to help Dekranasda as a developer and facilitator to build awareness of this brand, then increase the sales of Sasirangan Banjarbaru.

Keywords: Embroidery, Sasirangan Banjarbaru, visual branding

${ }^{1}$ Mahasiswi Program Studi DKV Telkom University, email: azizah.septiningtyas@gmail.com

2Pengajar Program Studi DKV Telkom University, email: widiatmokodw@gmail.com 


\section{PENDAHULUAN}

Setiap daerah memiliki warisan budaya lokal yang dilestarikan hingga kini, dapat berupa adat istiadat, kerajinan tangan hingga makanan khas. Kerajinan tangan dengan ciri budaya lokal kini sering dijadikan buah tangan dari daerah tertentu. Provinsi Kalimantan Selatan memiliki berbagai jenis kerajinan tangan, salah satunya pada bidang sandang yaitu kain Sasirangan, adalah selembar kain putih yang dijahit dengan teknik jelujur, diikat dan kemudian dicelup atau disemprot dengan warna, akan menghasilkan motif tertentu sesuai bekas jahitan dan ikatan yang dibuat sebagi perintang pewarnaan.

Kain ini sudah ada sejak abad ke 12, dikenal dengan nama Kain Pamintan, kain ini dahulu merupakan benda sakral yang digunakan sebagai 'batatamba' atau media pengobatan alternatif non medis. Dengan adanya pengaruh modernisasi, Kain Sasirangan mengalami inovasi dari segi motif, kegunaan serta warna. Sekarang ini sudah tidak ada lagi yang menggunakan kain ini sebagai media pengobatan. Kain Sasirangan modern lebih banyak diolah untuk dijadikan baju atas formal, busana kerja ataupun busana bawah seperti rok. Kain Sasirangan memiliki aneka motif sirang dan warna-warna yang khas, seperti kuning, hijau, ungu, merah, hitam serta coklat.

Dengan perkembangan tren mode di Indonesia saat ini, membuat orang orang ingin tampil menggunakan kain tradisi namun lebih percaya diri serta menawan dengan berbagai mode terbaru. Perajin-perajin melihat adanya kesempatan untuk menaikkan posisi kain tradisional Kalimantan Selatan menjadi salah satu trendsetter fashion yang tidak kalah saing dengan mode barat seperti saat ini. Para perajin khususnya yang berada di Kota Banjarbaru di bawah binaan Dewan Kerajinan Nasional Daerah (Dekranasda) Kota Banjarbaru, melakukan inovasi berupa penambahan bordir di sekitar motif-motif Sasirangan. Hal itu menyebabkan terciptanya Sasirangan Bordir, yang menjadi ciri khas dari Kota Banjarbaru. Untuk itu, penelitian ditujukan pada Sasirangan Bordir Banjarbaru, 
yang memiliki keunggulan yaitu penambahan bordir sekitar motif menyebabkan warna serta motif yang ada pada kain terlihat lebih cerah dan timbul. Inilah yang menyebabkan Sasirangan Bordir Banjarbaru berbeda dengan Sasirangan pada umumnya. Pemilihan warna-warna saat ini juga lebih beragam, sehingga perajin dapat mengembangkan sesuai warna-warna yang sedang tren di pasaran.

Keberadaan Sasirangan Bordir Banjarbaru sudah ada sekitar tahun 2012, namun kurang lancarnya pemasaran membuat masyarakat kurang mengetahui tentang Sasirangan Bordir Banjarbaru. Hal tersebut berdampak pada sulitnya perajin memenuhi target penjualan Sasirangan Bordir Banjarbaru. Dari hasil wawancara, dapat disimpulkan bahwa Dewan Kerajinan Nasional Daerah telah melakukan kegiatan pengembangan seperti promosi melalui pameran dan kunjungan dinas serta pro aktif dalam menggunakan channel pemasaran word of mouth di setiap perjalanan dinas.

Kegiatan promosi tersebut memberikan dampak yang signifikan dengan booming-nya Sasirangan Bordir Banjarbaru di tahun 2016, dimana pemasaran mengalami peningkatan. Namun, menurut hasil kuesioner dimana responden berusia 21-40 tahun yang mewakili masyarakat, dari 54 orang hanya 24 orang yang mengetahui Sasirangan Bordir Banjarbaru. Didukung oleh hasil wawancara, promosi Sasirangan Bordir Banjarbaru masih perlu dilakukan, karena sesuai perkembangan zaman maka perlu ditumbuhkan kepedulian terhadap kain tradisional sebagai cinderamata khususnya bagi kelompok sasaran dewasa muda. Selain itu belum adanya identitas visual dan kemasan, yang belum menarik perhatian dan kepedulian target audience. Untuk mengatasi hal tersebut, Dewan Kerajinan Nasional Daerah perlu merancang identitas visual, packaging dan promosi yang sesuai dengan target audience Sasirangan Bordir Banjarbaru. Hasil perancangan ini diharapkan dapat membantu meningkatkan kepedulian masyarakat terhadap kain tradisional, sekaligus dapat mencapai target penjualan yang ingin dicapai. 


\section{KAJIAN TEORI}

Dalam buku Branding memaparkan bahwa brand merupakan hal yang penting bagi pelanggan, perusahan dan stake holder, brand sebuah tanda yang dapat berupa identitas visual seperti logo, maskot, packaging, tagline, jingle dan lain lain dimana dapat membedakan dengan pesaing sejenis (Swasty, 2016:5). Logo sebagai representasi banyak elemen yang berbeda-beda dan menggabungkannya ke dalam sebuah sistem yang lengkap.

Desain memainkan peran yang penting dalam menciptakan dan membangun sebuah brand, mengekspresikan emosi, sesuatu yang dapat dirasakan oleh indera kita, keadaan itu merupakan hal yang paling penting bagi khalayak sasaran (Arika \& Soewardikoen 2014 : 87). Dalam pembuatan logo ada beberapa hal yang perlu dipertimbangkan untuk membuat logo yang baik mencakup Original dan Destinctive (ciri khas, bentuk unik), Legible (terbaca di berbagai media dan ukuran), Simple (sederhana), Memorable (mudah diingat), Easily associated with company (logo dapat dan mudah diasosiasikan dengan citra entitas) (Carter dalam Kusrianto, 2009:234).

Kemasan merupakan suatu wadah atau tempat dimana dapat meningkatkan nilai dan fungsi dari sebuah produk (Julianti, 2014:15). Kemasan dapat memberikan positioning pada produk tersebut dengan rancangan estetika visual seperti warna, struktur fisik, simbol atau angka dan tipogragi, sehingga menarik perhatian target audience (Klimchuk \& Krasovec, 2007:84). Pemasaran sangat diperlukan bagi setiap produk, untuk melancarkan pemasaran perlu adanya kegiatan kombinasi promosi yang persuasif dan inovatif dimana dapat mengkomunikasikan perusahaan dengan pelanggan untuk meningkatkan penjualan produk (Belch, dkk 2009:16-18). Model AISAS merupakan tahapan penyebaran media promosi untuk penentuan media promosi yang akan digunakan, disesuaikan dengan percepatan penyebaran informasi di kalangan masyarakat saat ini (The Dentsu Cross Switch Team, 2012). 
Tipografi merupakan salah satu elemen desain, dimana berfungsi untuk menunjang komunikasi yang memberikan pesan yang dapat dibaca secara jelas dan tepat, selain itu secara estetika pesan dapat terlihat menarik (Sihombing, 2015). Ilustrasi dapat memudahkan pembaca untuk menggambarkan informasi. Tujuan utama dari sebuah ilustrasi untuk menarik perhatian pembaca, serta untuk mengkomunikasikan ide dan gagasan iklan sehingga iklan dapat dipercaya (Soewardikoen, 2015:121). Menurut Kartika dan Wijaya, warna adalah sesuatu yang melengkapi pada suatu desain identitas, yang memiliki arti dan makna dari identitas entitas yang ditunjang dengan kualitas dan komposisi (Kartika dan Wijaya, 2015:35). Layout merupakan suatu elemen desain dimana berfungsi untuk mengatur penempatan judul, subjudul, ilustrasi dan bodycopy agar komunikatif yang lebih efektif (Soewardikoen, 2015:119).

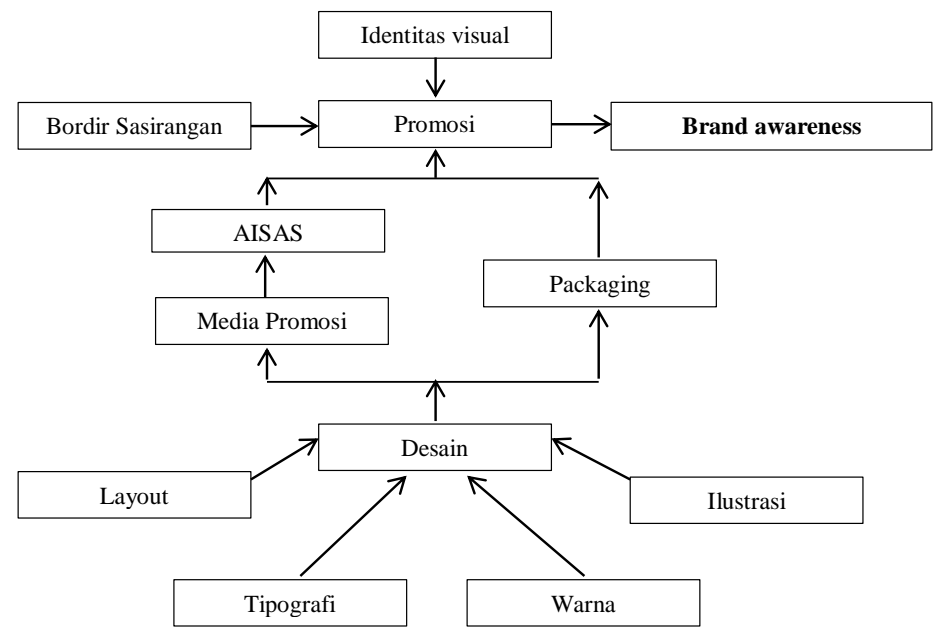

Bagan 1. Kerangka Teori

Sumber : Septiningtyas, 2017:27

\section{METODE PENELITIAN}

Pengumpulan data dilakukan dengan instrumen kuesioner, wawancara, dokumentasi, studi pustaka dan pengamatan visual. Kemudian data yang diperoleh dianalisis dengan menggunakan matriks perbandingan. 
Setiap karya visual selalu terdiri dari tiga aspek, yaitu aspek gambar atau imaji, aspek pembuat atau produksi imaji, dan aspek pemirsa. Masing masing aspek mempunyai akses kepada peneliti sehingga dapat mengaksesnya dengan metoda tertentu (Soewardikoen, 2013 : 23). Dalam perancangan ini untuk aspek imaji pengamatan dilakukan pada objek penelitian, yaitu Sasirangan Bordir Banjarbaru di Propinsi Kalimantan Selatan. Pengamatan yang dilakukan mencakup objek produk Sasirangan Bordir, objek visual promosi produk sejenis dan kegiatan pemasaran Dewan Kerajinan Nasional Daerah, serta sample target audience dari toko cinderamata lain.

Pengamatan ini didukung dengan dokumentasi yang dilakukan selama proses pengamatan untuk memperoleh data awal. Data dari aspek pembuat didapatkan melalui wawancara mendalam kepada Kepala Humas Dewan Kerajinan Nasional Daerah Kota Banjarbaru serta beberapa perajin di Kota Banjarbaru. Data dari pemirsa didapatkan dengan menyebarkan kuesioner secara acak kepada 90 orang responden untuk mengetahui tanggapan dari masyarakat terhadap mediamedia potensial bagi target audience, serta untuk mengetahui bagaimana promosi yang diharapkan target audience agar Sasirangan Bordir Banjarbaru dapat dikenal.

Adapun studi pustaka dilakukan untuk acuan dalam perancangan ini yaitu meliputi sejarah Sasirangan, identitas visual, packaging, promosi dan tahapannya serta teori lain yang berkaitan dengan Desain Komunikasi Visual melalui berbagai sumber buku, jurnal, artikel dan internet. Untuk membantu dalam proses penelitian ini, matriks perbandingan dibuat terhadap produk sejenis. Dalam hal ini, produk sejenis yang dijadikan objek perbandingan adalah usaha kerajinan Sasirangan Diyang Kinjut, Sahabat Sasirangan dan Irma Sasirangan.

\section{HASIL DAN DISKUSI}

Sasirangan Bordir Banjarbaru merupakan produk cinderamata Sasirangan khas Kota Banjarbaru, yang memiliki keunikan pada warna-warna cerah, serta 
bordir menimbulkan warna serta motif sirang lebih terlihat. Sasirangan Bordir Banjarbaru sudah diciptakan sejak tahun 2012, namun pemasaran baru mulai meningkat pada tahun 2016. Ketika awal tahun 2017 target penjualan sudah mencapai kurang lebih $80 \%$. Hal itu sebagai hasil dari program pengembangan dari Dewan Kerajinan Nasional Daerah Kota Banjarbaru dengan bekerja sama dengan Pemerintah Kota Banjarbaru dan beberapa instansi dalam memasarkan pada setiap kunjungan dinas, pameran serta proaktif dalam menggunakan channel word of mouth.

Saat ini juga sedang dicanangkan pembuatan kota wisata oleh Pemerintah Kota, ditandai dengan akan dibangunnya sebuah sentra cinderamata khas Kota Banjabaru yang menjadi harapan bagi perajin dan pelaku usaha untuk lebih giat memasarkan Sasirangan Bordir Banjarbaru.

Dewan Kerajinan Nasional Daerah Kota Banjarbaru sebagai fasilitator sudah menggunakan beberapa media promosi dalam setiap pameran yang diikutinya, seperti xbanner serta brosur. Sudah disadari akan pentingnya penggunaan media digital sebagai media promosi yang optimal saat ini. Namun mereka mengaku belum menjangkau para pengguna media digital sebab kekurangan Sumber Daya Manusia untuk mengelola media tersebut. Para perajin yang sadar akan pentingnya media digital saat ini mulai mandiri dengan mengunggah produk ataupun testimoni dari konsumen.

Dalam hal visual, mereka belum dapat fokus dan memaksimalkan dari segi estetis promosi yang dilakukan. Mereka masih mementingkan pengembangan dan penguatan kualitas produknya agar memiliki keunggulan yang dapat ditawarkan pada calon konsumen. Maka dari itu, Dewan Kerajinan Nasional Daerah dapat lebih fokus pada pengembangan promosi. Hal ini dikuatkan dari hasil kuesioner, dari 90 orang responden terdapat 54 orang responden valid. Dari 54 orang tersebut, 30 orang tidak mengetahui Sasirangan Bordir Banjarbaru. 
Hal ini menyatakan bahwa lebih dari setengahnya belum mengetahui Sasirangan Bordir Banjarbaru. Penyebabnya adalah tidak adanya identitas dan promosi. Menurut mereka, penting sekali bagi suatu produk baru mengenalkan identitas produk mereka serta mempromosikan produk baru mereka agar target audience potensial mengetahuinya. Responden juga berpendapat bahwa penentuan media juga mempengaruhi dampak promosi yang dilakukan. Penggunaan media digital lebih diunggulkan karena akses yang dapat dijangkau dengan mudah oleh mereka. Namun tidak menutup kemungkinan media-media promosi konvensional juga dibutuhkan karena beberapa target audience potensial masih menggunakan cara konvensional untuk memperoleh informasi.

Adanya identitas visual juga sangat diharapkan agar mereka dapat mengenali produk yang sedang dipromosikan. Pengemasan yang rapi dan estetis juga diharapkan oleh responden terhadap produk Sasirangan Bordir Banjarbaru. Berdasarkan hasil wawancara, kuesioner dan matriks perbandingan terhadap ketiga produk sejenis, diketahui bahwa logo itu sangat penting bagi produk Sasirangan, namun logo yang sudah ada didominasi oleh penggunaan nama dari produk tersebut. Packaging yang ada sudah menerapkan elemen desain yang sama dan senada dengan promosi dan identitas visual, namun penggunaan struktur packaging masih monoton serta terkesan sama pada setiap merk.

Selain identitas visual dan packaging, media promosi juga perlu diperhatikan, karena masih digunakan media-media yang konvensional. Belum adanya kesenadaan pada elemen desain masing-masing media promosi yang dibuat, hanya ada beberapa desain sudah memiliki konsistensi. Di era digital saat ini, masyarakat lebih mudah menjangkau dan mengakses informasi melalui media berbasis internet, sehingga pameran, kunjungan dinas ataupun word of mouth dirasa belum optimal. Media konvensional yang telah dilakukan dapat berfungsi secara optimal bila dipadu-padankan dengan media digital. 


\section{KONSEP PERANCANGAN}

Pesan utama yang akan disampaikan kepada target audience adalah "Sasirangan Banjarbaru bergaya etnik sebagai cinderamata khas Kota Banjarbaru". Untuk nama identitas yang direkomendasikan yaitu "Sasirangan Banjarbaru" agar lebih langsung terasosiasi pada produk cinderamata Banjarbaru. Untuk lebih mendukung identitas tagline yang direkomendasikan adalah "Percaya Diri Pakai Sasirangan Banjarbaru". Penggunaan nama identitas serta tagline yang vulgar didasari pada produk ini produk baru sehingga identitas ingin ditonjolkan agar asosiasi langsung mengarah pada Sasirangan Banjarbaru.

Selain itu identitas dan tagline ini digunakan untuk mengkomunikasikan dan mempromosikan keunggulan produk secara langsung pada target audience, dimana pada tahap pengenalan target audience sadar dan memiliki perhatian terhadap adanya produk ini, serta diharapkan adanya ketertarikan dan memutuskan untuk membeli Sasirangan Banjarbaru, sehingga meningkatkan pemasaran dan penjualan Sasirangan Banjarbaru.

Konsep Kreatif. Perancangan ini menggunakan pendekatan secara emosional pada target audience dengan menggunakan tagline “Percaya Diri Pakai Sasirangan Banjarbaru". Ide konsep ini berdasar pada psikografis target audience yang mampu menciptakan e-wom (electronic word of mouth) dengan saling membagikan informasi dan pengalaman mereka akan sesuatu berupa foto, video ataupun teks. Selain itu dengan perkembangan digital, orang dapat berekspresi sesuka mereka, terlebih pada target audience yang suka membagikan pengalaman mereka pada bidang fashion. Melalui e-wom tersebut, target audience diajak untuk memakai produk etnik yang inovatif dapat dipakai semi formal maupun casual, kemudian mereka akan membagikan pengalaman mereka dengan percaya diri saat mengenakannya. Sehingga promosi dapat berjalan dengan optimal.

Kata "Percaya Diri" pada tagline ingin menyampaikan bahwa dengan memakai produk Sasirangan Banjarbaru ini dapat membuat tampilan target 
audience lebih baik dan indah. Walaupun produk ini lokal, etnik, namun produk ini inovatif pada pengaplikasian bordir serta penggunaan warna cerah. Hal inilah yang membuat penggunaSasirangan, lebih percaya diri.

Konsep Visual. Dalam menarik perhatian target audience melalui identitas visual Sasirangan Banjarbaru, hal pertama yang dilakukan yaitu mengembangkan elemen-elemen visual pada logo yang mampu merepresentasikan kualitas produk, filosofi produk serta visi dan misi dari Sasirangan Banjarbaru. Elemen-elemen visual ini nantinya akan diterapkan secara konsisten dan saling keterkaitan secara menyeluruh pada setiap media promsi yang akan digunakan guna terciptanya brand awareness yang diharapkan.

Pada perancanangan desain nantinya diambil dari elemen unsur visual pendukung logo yang dapat mempengaruhi gaya visual, seperti (1) Fotografi menggunakan model couture. Fotografi model, dengan teknik couture akan memberikan kesan keindahan detail produk bila dipakai oleh model. (2) Warna menggunakan warna kuning dan biru. Kuning mewakili dari warna khas Suku Banjar, sedangkan biru menggambarkan hal inovatif dengan adanya inovasi pengaplikasian bordir pada Sasirangan. (3) Tipografi menggunakan jenis Sans Serif, dengan nama font Source Sans Pro dan Raleway. Font ini dipilih karena karateristik huruf dengan kerning yang tidak terlalu dekat dan jauh itu mengakibatkan huruf tersebut mudah serta jelas untuk dibaca. (4) Layout yang dipilih yakni asimetris agar terlihat lebih dinamis dan masa kini, serta pada layout dapat menonjolkan foto produk sebagai emphasis dalam layout. Unsur-unsur visual tersebut akan dijadikan elemen visual berdasarkan penggambaran percaya diri, etnik inovatif dan cinderamata khas Kota Banjarbaru.

Identitas Visual. Berdasarkan hasil data dan analisis, dibutuhkan perancangan identitas berupa logo, yang pertama akan dirancang. Logo yang sering digunakan yaitu tipe logotype. Perancangan identitas visual disini membuat logotype mengambil tipografi dari font Source Sans Pro dengan jenis bold, font 
dikreasikan pada huruf ' $A$ ' agar logotype menjadi unik dan berciri khas. Jenis huruf Source Sans Pro dipilih untuk mewakili dari sudut pandang inovasi yang sesuai dengan tren visual dan desain saat ini. Sedangkan untuk logogram mengambil dari motif Hiris Gagatas dengan dipadukan motif Liukan yang bold dan garis putusputus, yang menandakan ciri khas dari bordir. Logogram ini mewakili sisi unsur etnik pada logo.
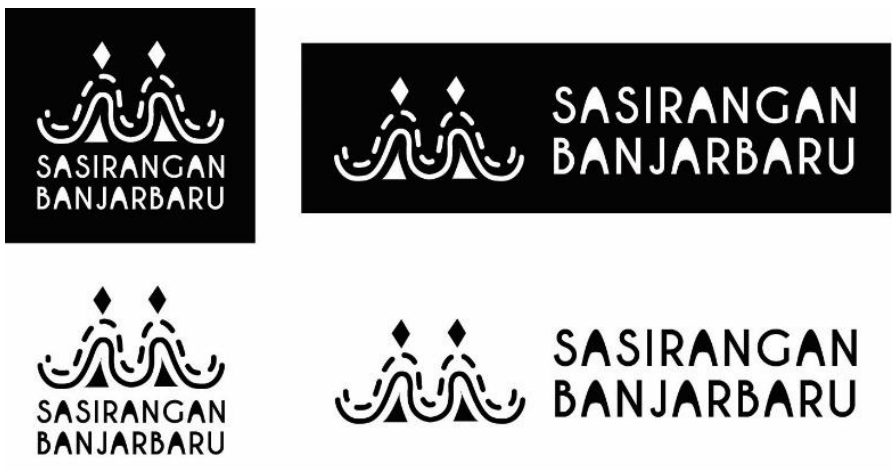
Gambar 1. Hasil Perancangan Logo Hitam Putih
Sumber : Septiningtyas, 2017:83

Berdasarkan konsep visual yang telah ditentukan, desain ini akan diaplikasikan pada setiap media promosi yang ada. Pada headline akan menjadi tujuan utama yang akan dilihat dengan diletakkan tulisan nama merk "Sasirangan Banjarbaru" dengan huruf Source Sans Pro. Setelah itu ilustrasi diletakkan dengan foto model di bawah headline pada sisi pinggir layout. Kemudian pada bodytext dengan tipe huruf Raleway bertuliskan dengan tagline "Percaya Diri Pakai Sasirangan Banjarbaru". Logo Sasirangan Banjarbaru dan Dewan Kerajinan Nasional Daerah Kota Banjarbaru di bagian bawah layout setelah tagline dengan saling bersandingan. Sebagai fungsi reminding pemberian contact pada bagian bawah layout, agar menjadi penarik bagi target audience untuk membuka media sosial ataupun website Sasirangan Banjarbaru. 


\section{SASIRANGAN
BANJARBARU}

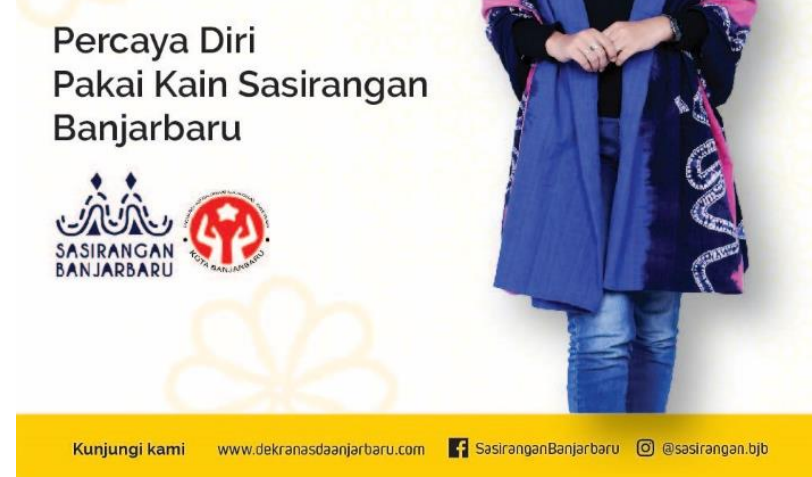

Gambar 2. Rancangan DesainMedia Promosi Sasirangan Banjarbaru Sumber : Septiningtyas, 2017:85

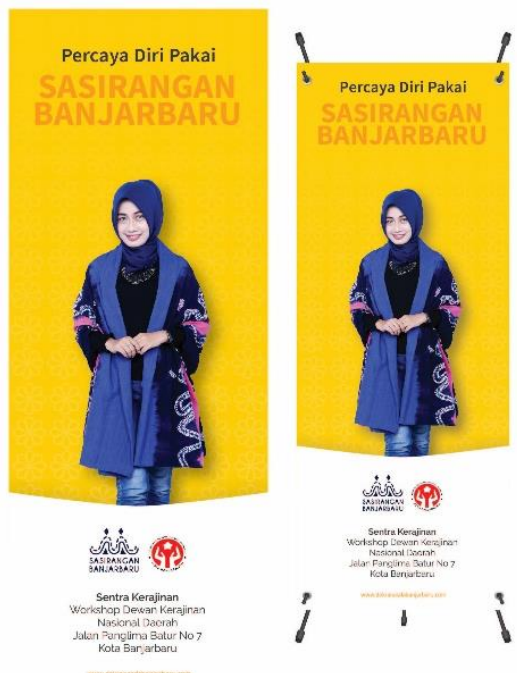

Gambar 3. Rancangan Banner Sumber : Septiningtyas, 2017:86 
Dalam perancangan ini, untuk memaksimalkan promosi yang akan dilakukan, diperlukan adanya media-media yang dapat mengkomunikasikan pesan promosi. Media promosi akan disesuaikan pada tahapan promosi model AISAS, agar penyampaian pesan dapat optimal diterima oleh target audience. Berikut media yang akan digunakan berdasarkan tahapan AISAS.

Tabel 1. Tahapan Promosi dengan model AISAS

\begin{tabular}{|c|c|c|c|}
\hline Tahapan & Media & Lokasi & Tujuan \\
\hline \multirow{6}{*}{ Attention } & Iklan Media Cetak & Koran dan Majalah & \multirow{6}{*}{$\begin{array}{l}\text { Untuk menarik } \\
\text { perhatian target } \\
\text { audience agar sadar } \\
\text { dengan produk } \\
\text { Sasirangan } \\
\text { Banjarbaru dengan } \\
\text { pesan singkat dan } \\
\text { desain yang menarik }\end{array}$} \\
\hline & Web Banner & Situs berita & \\
\hline & $e$-flyer & $\begin{array}{l}\text { Instagram dan } \\
\text { Facebook }\end{array}$ & \\
\hline & Media Table Info & $\begin{array}{l}\text { Lounge tempat } \\
\text { penginapan atau } \\
\text { hotel dan lounge } \\
\text { bandara }\end{array}$ & \\
\hline & Website & Internet & \\
\hline & Neon Box & $\begin{array}{l}\text { Terminal } \\
\text { kedatangan bandara } \\
\text { Syamsudin Noor } \\
\text { Banjarbaru }\end{array}$ & \\
\hline \multirow{5}{*}{ Interest } & e-flyer & $\begin{array}{l}\text { Instagram dan } \\
\text { Facebook }\end{array}$ & \multirow{5}{*}{$\begin{array}{l}\text { Untuk memberikan } \\
\text { kesan positif, } \\
\text { sehingga target } \\
\text { audience merasa } \\
\text { senang dan tertarik, } \\
\text { dengan informasi } \\
\text { secara detail serta } \\
\text { desain yang menarik }\end{array}$} \\
\hline & $\begin{array}{l}\text { Iklan Media Cetak } \\
\text { (Berita Advetorial) }\end{array}$ & Majalah dan Koran & \\
\hline & Web Banner & Situs Berita & \\
\hline & Brosur & $\begin{array}{l}\text { Pameran dan } \\
\text { workshop }\end{array}$ & \\
\hline & Website & Internet & \\
\hline \multirow[b]{3}{*}{ Search } & Website & Internet & \multirow{3}{*}{$\begin{array}{l}\text { Untuk menimbulkan } \\
\text { rasa ingin tahu lebih } \\
\text { pada target } \\
\text { audience terhadap } \\
\text { produk sehingga } \\
\text { mereka ingin } \\
\text { mencari tahu } \\
\text { tentang produk, } \\
\text { informasi lebih detail } \\
\text { dan desain yang } \\
\text { menarik, serta } \\
\text { mengarahkan target } \\
\text { audience pada tahap } \\
\text { Action }\end{array}$} \\
\hline & Media Sosial & $\begin{array}{l}\text { Instagram dan } \\
\text { Facebook }\end{array}$ & \\
\hline & Signage & Dekat Sentra & \\
\hline
\end{tabular}




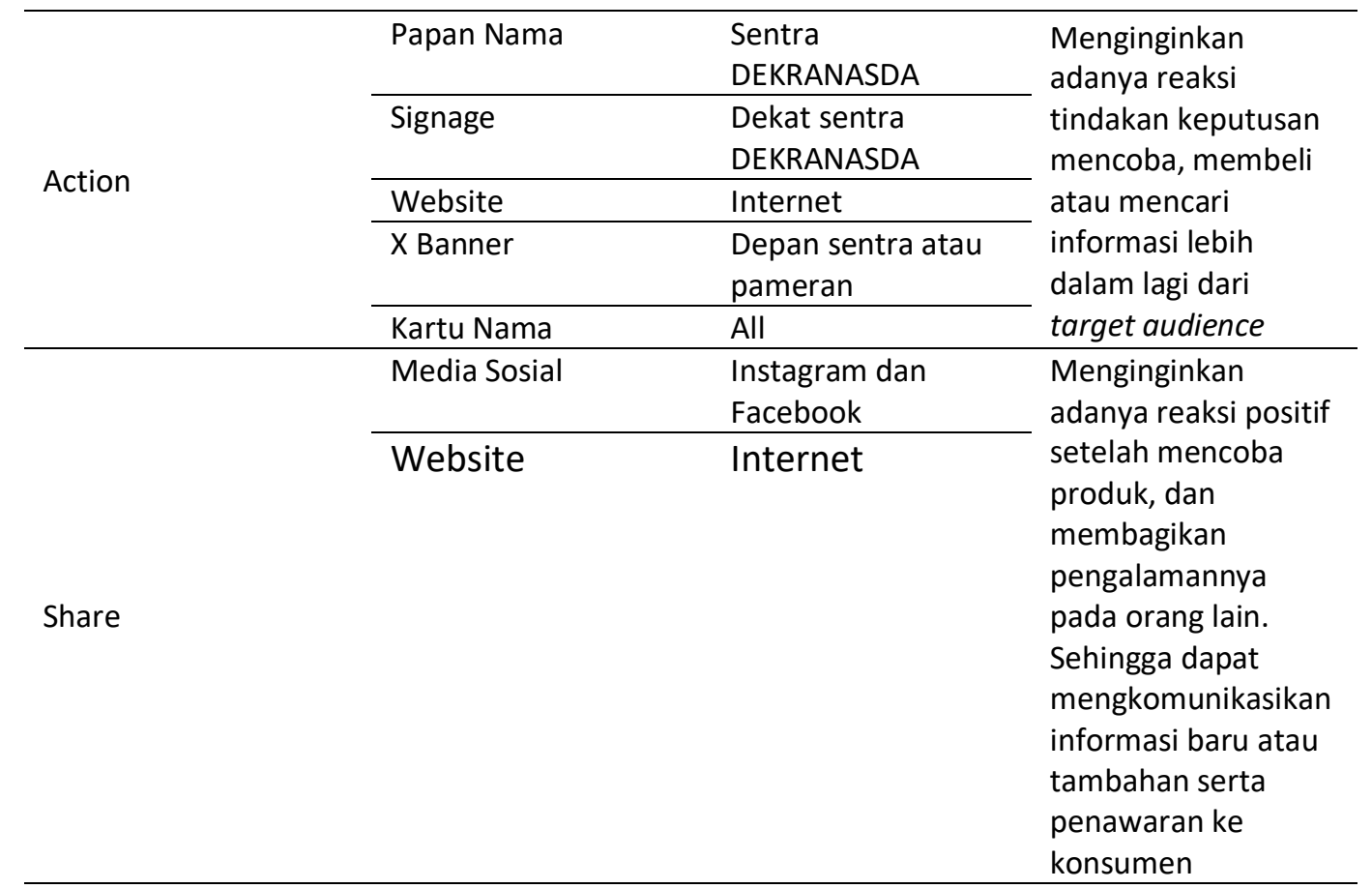

Sumber : Septiningtyas 2017

Berikut penjabaran hasil rancangan media promosi; (1) Kartu Nama. Perancangan kartu nama ini sebagai identitas visual yang dapat digunakan oleh target audience dapat menghubungi Sasirangan Banjarbaru serta pendekatan secara personal. (2) Kemasan. Dirancang dengan tujuan untuk menarik perhatian calon target audience serta melindungi kain Sasirangan Banjarbaru ketika dimobilisasi dengan desain yang dirancang. (3) Brosur. Brosur disini akan diletakkan pada showroom Sentra Dekranasda maupun pada stand saat pameran. Brosur ini bertujuan memberikan penjelasan dan informasi secara detail tentang Sasirangan Banjarbaru. Brosur juga berisi kontak yang dapat digunakan target audience untuk menghubungi pihak Sasirangan Banjarbaru.

(4) Neon Box. Perancangan media promosi ini akan diletakkan pada Terminal Kedatangan Bandar Udara Syamsudin Noor Kalimantan Selatan. Hal ini bertujuan untuk menarik perhatian penumpang yang baru datang di Kalimantan Selatan tentang Sasirangan Banjarbaru. (5) Web Banner. Di era digital ini target 
audience sudah mulai mengganti bacaan konvensional seperti koran dengan membuka situs berita disetiap. Perancangan media promosi ini agar mendekati target audience saat membuka situs berita tersebut. (6) Banner. Pada setiap pameran yang diikuti, dibutuhkan banner sebagai penanda dan penarik perhatian pengunjung agar tertarik mengunjungi stand. Banner ini berisi headline, fotografi, serta informasi lain seperti alamat lembaga, nomor kontak serta website. (7) Papan Nama. Perancangan media ini digunakan untuk sebagai identitas sekaligus penanda untuk target audience bisa mendapatkan Sasirangan Banjarbaru. (8) Signage. Media ini dirancang bertujuan mengarahkan target audience yang sedang berkunjung ke Banjarbaru, untuk memudahkan mereka sampai ke Sentra Dewan Kerajinan Nasional Daerah Kota Banjarbaru.

(9) Media Table Info. Target audience yang sedang melakukan perjalanan ke Kota Banjarbaru, dapat mendapatkan informasi singkat pada tiap Lounge tempat mereka menginap. (10) e-Flyer. Perancangan media promosi ini nantinya akan diletakkan secara elektronik di media digital seperti media sosial ataupun website. Dimana media ini berfungsi untuk memberikan informasi secara detail dengan memudahkan target audience untuk mengjangkaunya. (11) Iklan Cetak. Perancangan media promosi pada media massa konvensional masih diperlukan yang bertujuan untuk menjangkau target audience sekunder potensial dimana mereka masih membaca majalah ataupun koran. (12) Media Sosial. Perancangan media promosi pada media digital seperti media sosial yang dapat diakses setiap saat oleh target audience dimana mereka dapat informasi terbaru yang diperbaharui secara cepat seperti Instagram dan Facebook. (13) Website. Perancangan media ini nantinya berfungsi sebagai advetorial dengan artikelartikel yang mendokumentasikan kegiatan yang dilakukan oleh Dewan Kerajinan Nasional Daerah ataupun tentang Sasirangan Banjarbaru, selain itu dapat 
berfungsi sebagai media e-commerce, sehingga target audience nantinya dapat berbelanja Sasirangan Banjarbaru secara online.

\section{KESIMPULAN}

Perancangan identitas visual, packaging dan promosi Sasirangan Banjarbaru mampu membuat brand awareness, sehingga masyarakat luas dapat mengenal Sasirangan Banjarbaru serta memiliki ketertarikan membeli dan mampu menyebarluaskan informasi yang mereka punya ke orang lain. Kemasan digunakan untuk membungkus dan melindungi kain Sasirangan Banjarbaru selain itu dapat menambah daya tarik visual.

Media promosi disesuaikan dengan psikografis target audience dan tahapan penjadwalan media promosi dirancang agar informasi dapat tersampaikan dengan jelas kepada target audience. Semua perancangan ini dapat meningkatkan pemasaran Sasirangan Banjarbaru, sehingga berdampak pada pemberdayaan perajin sehingga dapat menaikkan taraf ekonomi masyarakat. Perancangan ini dapat berjalan dengan baik bila semua pihak yang ada di Dewan Kerajinan Nasional Daerah serta instansi terkait dapat bekerja secara sinergis dan terkoordinasi dengan baik.

\section{DAFTAR PUSTAKA}

Arika, R., Soewardikoen, D. W., (2014) Brand Identity Design Of The Bay Bali, Jurnal Wimba, Vol.6, No.2 halaman 87, http://jurnalwimba.com/index.php/ wimba/article/view/105/pdf 74, diakses 1 Agustus 2017

Belch, George E. \& Michael A. (2009). Advertising and Promotion - An Integrated Marketing Communications Perspective Eigth Edition. New York : The McGraw-Hill Companies, Inc Julianti, Sri. (2014). The Art of Packaging. Jakarta : PT. Gramedia Pustaka Utama 
Kartika, Jessica Diana \& Wijaya, Rudyant Siswanto. (2015). Logo : Visual Asset Development. Jakarta : Gramedia Publisher

Klimchuk, Marianne Rosner \& Sandra A. Krasovec. (2007). Desain Kemasan : Perencanaan Merek Produk yang Berhasil Mulai dari Konsep sampai Penjualan. Jakarta : Penerbit Erlangga

Kusrianto, Adi. (2007). Pengantar Desain Komunikasi Visual. Yogyakarta : CV. Andi Offset

Seman, Syamsiar. (2013). Sasirangan Kain Khas Banjar. Banjarmasin : Lembaga Pengkajian dan Pelestarian Budaya Banjar Kalimantan Selatan

Septiningtyas, Azizah. (2017). Perancangan Identitas Visual, Packaging dan Promosi untuk Sasirangan Banjarbaru. Laporan Tugas Akhir. Openlibrary Telkom University

Sihombing, Danton. (2015). Tipografi Dalam Desain Grafis - Edisi Diperbaharui. Jakarta : PT. Gramedia Pustaka Utama

Soewardikoen, Didit Widiatmoko. (2013). Metodologi Penelitian Visual dari Seminar ke Tugas Akhir. Bandung : CV. Dinamika Komunika

Soewardikoen, Didit Widiatmoko. (2015). Visualisasi Iklan Indonesia Era 19501957 Edisi 2. Yogyakarta : Calpulis

Swasty, Wirania. (2016). Branding : Memahami dan Merancang Strategi Merek. Bandung : PT. Remaja Rosdakarya

The Dentsu Cross Switch Team, 2012. Cross Communication Glossary [eDictionary] Japan : Dentsu. Tersedia di http://www.dentsu.com/crossswitch /dictionary/ index.html [Diakses 10 April 2017 20:43] 